\title{
Comparison of different methods of $A B I$ acquisition for detection of peripheral artery disease in diabetic patients
}

\author{
Miroslav Homza ${ }^{\mathrm{a}, \mathrm{b}}$, Ondrej Machaczka ${ }^{c}$, Martin Porzer ${ }^{\mathrm{a}, \mathrm{b}}$, Milan Kozak ${ }^{\mathrm{d}}$, Jiri Plasek ${ }^{\mathrm{a}, \mathrm{b}}$, David Sipula ${ }^{\mathrm{a}, \mathrm{b}}$
}

Background. Ankle brachial index (ABI) is the principal screening method for peripheral arterial disease (PAD). In this study, we compare various types of Doppler-derived and oscillometric ABIs with results obtained through duplex ultrasonography.

Methods. 62 patients were enrolled in the study. For each limb, blood pressures for both ankle arteries and the arm were measured using Doppler and an automated oscillometric device. Duplex ultrasound was performed for all limbs and occlusions $>50 \%$ were considered PAD-positive. ABI was calculated using both higher (HABP) and lower (LABP) arterial blood pressure on the individual limbs and the ability to predict duplex-detected stenoses was evaluated.

Results. LABP calculation provided results superior to the guideline-recommended HABP. Considering patients with $A B I>1.4$ or measurement failure as PAD-positive further enhanced the test parameters. The higher ABI cut-off of 1.0 resulted in somewhat better sensitivities ( $\max 92 \%$ ) and negative predictive values (max $87 \%$ ) at the expense of a substantial increase in the number of false positives. Oscillometric method yielded poor sensitivities but very good specificities (max 94\%) and positive predictive values ( $\max 90 \%$ ).

Conclusions. Doppler-based LABP provides better results than the guideline-recommended HABP in diabetic patients, nevertheless even this method is not perfect. Increasing the cut-off value to 1.0 in these patients does not bring a substantial improvement of the test performance. Patients with high ABI should be automatically considered PADpositive and referred for further investigation using imaging techniques.

Key words: ankle brachial index, diabetes, oscillometric measurement, dopplerometric measurement, duplex ultrasonography

Received: May 7, 2018; Revised: July 9, 2019; Accepted: August 10, 2018; Available online: September 14, 2018 https://doi.org/10.5507/bp.2018.046

(c) 2019 The Authors. This is an open access article licensed under the Creative Commons Attribution License (https://creativecommons.org/licenses/by/4.0/).

${ }^{a}$ Department of Cardiovascular Diseases, University Hospital Ostrava, Czech Republic ${ }^{b}$ Department of Internal Medicine, Faculty of Medicine, University of Ostrava, Czech Republic 'Department of Epidemiology and Public Health, Faculty of Medicine, University of Ostrava, Czech Republic ${ }^{d}$ Department of Internal Cardiology Medicine, Faculty of Medicine, Masaryk University Brno, Czech Republic Corresponding author: Miroslav Homza, e-mail: mirek.homza@centrum.cz

\section{INTRODUCTION}

Peripheral arterial disease (PAD) is a widespread disease affecting over 154 mil people worldwide ${ }^{1}$. It constitutes a major risk factor for amputation of lower limbs as well as for myocardial infarction, ischemic stroke, and cardiovascular death ${ }^{2}$. In a majority of PAD patients, the PAD is largely asymptomatic, making it difficult to detect ${ }^{3}$.

The principal screening method for PAD is the anklebrachial index measurement, $\mathrm{ABI}\left(\right.$ ref. $\left.^{3}\right)$. The method is based on measurement of systolic blood pressure (SBP) by a Doppler probe $(5-10 \mathrm{MHz})$ on the posterior and anterior tibial arteries of each foot and on the brachial artery of each arm. The ABI of each leg is calculated by dividing the highest ankle SBP by the highest arm SBP (ref. ${ }^{4}$ ). The normal ABI ranges from 1.00 to 1.40 and values $\leq 0.90$ are considered as PAD indicators. ABI values of 0.91 to 0.99 are considered "borderline" while values over 1.40 indicate non-compressible arteries ${ }^{46}$ associated with vascular calcifications, potentially bearing an even more serious effect on the quality of life than low ABI (ref. ${ }^{7-9}$ ). The guidelines recommend use of the higher SBP from the two arteries at the ankle level for ABI calculation. It has however been shown to yield worse correlations with the presence of PAD than the opposite - use of the lower of those SBPs (ref. ${ }^{10-12}$ ).

Another possible source of variability in the use of $\mathrm{ABI}$ for screening is the measurement of the systolic blood pressure itself. The dopplerometric method is still considered a gold standard in ABI measurement but it is prone to a notable interobserver variability ${ }^{13,14}$. For this reason, oscillometric method using automated devices has been tested in numerous studies. The correlations between oscillometric ABI, Doppler ABI and actual PAD presence determined by colour duplex sonography or by angiography however vary greatly from excellent ${ }^{14,15}$ through good results $^{16-18}$ to inconclusive or poor results ${ }^{13,19,20}$.

Despite the fact that $\mathrm{ABI}$ is recommended as a screening method in diabetic patients ${ }^{2,21}$, it is generally accepted that $\mathrm{ABI}$ is not as reliable in that group, especially due 
to a relatively higher fraction of patients with non-compressible arteries ${ }^{7,22}$.

Studies dedicated to a comparison of ABI results obtained with oscillometric devices and Doppler measurement with actual PAD data focused solely on the high-risk group of diabetic patients are still rare. For this reason, we performed a prospective study in a group of diabetic patients in whom PAD presence or absence was determined using duplex ultrasound scanning (DUS). These data were compared with ABIs derived in several ways; besides the guideline-recommended method, we also used alternate ABI calculation using the lower ankle pressure and ABI measured by oscillometry. To our best knowledge, no prospective study comparing all these factors simultaneously in the same cohort of solely diabetic patients has been published to date.

The aims of our study were a) to evaluate the screening performance of $\mathrm{ABI}$ (sensitivity, specificity, negative and positive predictive values) in a cohort of diabetic patients, b) to compare several methods of $\mathrm{ABI}$ acquisition and c) to explore the effect of increasing the cut-off value of $\mathrm{ABI}$ from 0.9 to 1.0 on the screening results.

\section{METHODS}

The study group comprised 62 consecutive diabetic patients presenting to our cardiovascular outpatient clinic in Ostrava, Czech Republic. All patients participating in the study were fully briefed, volunteered for the study and signed an informed consent.

Exclusion criteria - Age $<18$, critical limb ischemia (Fontaine III, IV/Rutherford 4-6), any limb amputation, renal failure grade $\mathrm{G} 5$ according to CKD KDIGO G5 $\left(\right.$ ref. $\left.^{23}\right)$, any active cancer.

All measurements were performed in the morning hours during one visit in the same sequence. After taking the full medical history and basic measurements (height, weight), the oscillometric ABI measurement was performed. The patient rested in a supine position in a room tempered at $22{ }^{\circ} \mathrm{C}$ for $10 \mathrm{~min}$ prior to the measurement. An automated device Boso ABI-system 100 (Bosch+Sohn, Germany) simultaneously recording blood pressure on all four limbs and calculating ABI was used in accordance with the device manual using appropriately sized sphygnomanometric cuffs.

Doppler measurements were performed in accordance with AHA guidelines for ABI measurement ${ }^{24}$. A digital vascular doppler HUNTLEIGH Dopplex DMX (Huntleigh Healthcare, United Kingdom) with an 8 $\mathrm{MHz}$ probe was used to measure the individual systolic pressures. An appropriately sized pneumatic cuff was applied to the right upper arm, inflated to suprasystolic pressure and deflated slowly until a Doppler flow signal was detected. The process was repeated for right leg and values for both dorsal pedal and anterior tibial arteries were measured, followed by left leg and left arm. ABI was subsequently calculated for each lower limb separately using the value of pressure from the respective arm as a denominator. Where any of the systolic pressures could not be measured, the fact was recorded and used for subsequent analyses (see below).

Due to the low overall Fontaine grading in our patient group, it was not possible to use angiography for acquisition of the reference data (ethical reasons). Hence, we used duplex ultrasound scanning as the gold standard. DUS was performed using Vivid S6 Ultrasound System (GE Healthcare, USA) equipped with 8L-RS (a 5-13 MHz linear transducer) and 4C-RS (1,8-6 MHz curvilinear transducer). Each limb was examined in the proximal to distal direction with the patient in a supine position. Any stenosis was recorded, stenosis $>50 \%$ was considered as a proof of PAD presence and used for subsequent analysis.

The obtained results were processed in MS Excel (Microsoft, USA). The following ABI values were calculated for each limb: ABI ATP - calculated by dividing systolic blood pressure of the posterior tibial artery by the systolic blood pressure from the respective arm; ABI ADP - the same using data from the dorsalis pedis artery; ABI HABP/ABI LABP - derived from the higher/lower of the two ankle blood pressures on the same leg; ABI OSC - oscillometric measurement - was not calculated but directly recorded from the BOSO ABI system 100 device.

Subsequently, confusion matrices detailing results of individual ABI categories when compared to occlusions detected by DUS were prepared and test parameters (sensitivity; specificity; positive predictive value - PPV; negative predictive value - NPV; false positive and false negative rates) were calculated. To further analyze the "borderline" ABIs, i.e., the ABI range from 0.9 to 1.0 , the confusion matrices were prepared and test parameters calculated both for $\mathrm{ABI}<0.9$ and $\mathrm{ABI}<1.0$.

To evaluate the situation in patients whose ABI was higher than 1.4 and those in whom any of the measurements failed, the same analysis was performed both including and excluding thus affected limbs from the analysis. When including them, the limbs with abnormally high/unobtainable ABI were considered as PAD-positive in the analysis.

\section{RESULTS}

62 diabetic patients were recruited in the study, 46 of which were male and 16 female. The mean age was 67.6 years. The group characteristics are summarized in Table 1.

Table 2 shows test parameter calculations for individual limbs using two cut-off values for PAD detection - ABI 0.9 as prescribed by guidelines and 1.0 as an alternate suggestion for the diabetic patients. These parameters were calculated both with exclusion of any patients in whom ABI could not be obtained or was >1.4 (14-16 limbs out of 124 for all ABI calculations except for ABI HABP with 26 limbs excluded in this way) and without such exclusion with abnormally high values perceived as a proof of the disease.

Table 2 shows that the best sensitivities and negative predictive values were recorded throughout all calculations for ABI LABP. Using the higher cut-off value of 1.0 
instead of 0.9 improved the sensitivity at the expense of specificity. However, the negative predictive values did not drop with this higher cut-off value, they even increased. Similarly, when all limbs with abnormally high ABI or SBP measurement failure were included in the dataset as "PAD-positive", the test parameters did not drop as expected but even improved somewhat. Still, however, neither of the methods provided fully satisfactory results.

Oscillometric measurements showed a completely different picture than the LABP method. It yielded poor sensitivities, however with an excellent specificity and positive predictive values for the cut-off 0.9. As for LABP, when limbs with $\mathrm{ABI}>1.4$ or measurement failure were included into the dataset, it further improved the performance of the test. However, the effect of increasing the cut-off to 1.0 led understandably to poorer results for oscillometric measurement, improving sensitivity somewhat at the expense of specificity and PPV.

\section{DISCUSSION}

Diabetes is one of the major risk factors for developing PAD (ref. ${ }^{25}$ ). Hence, the fact that ABI is suggested to be an unreliable PAD indicator in diabetic patients deserves further investigation. In our study, we used several approaches towards determining $\mathrm{ABI}$ (oscillometric, Doppler HABP and LABP) in diabetic patients and related the results to "true PAD" data determined by DUS. It is worth emphasising that in this study, we do not consider ABI to be a diagnostic tool but rather to be a screening tool intended to determine if the screened patients are PAD-free or if they are likely to have PAD and therefore should undergo a more specialized examination (such as DUS).

The results from the Table 2 and 3 indicate that although none of the tests was perfect for the screening of PAD, ABI LABP consistently yielded the best results in terms of sensitivity and negative predictive value.
Table 1. Characteristics and risk factors for the study group.

\begin{tabular}{lc}
\hline General characteristics & $\begin{array}{c}\text { Mean } \\
(\min ; \mathrm{max})\end{array}$ \\
\hline Age (years) & $67.6(41.8 ; 83.2)$ \\
BMI & $30.8(22.8 ; 46.7)$ \\
Sex (male/female) & $46 / 16$ \\
Diabetes + treatment & \\
$\quad$ Years from DM diagnosis & $8(0 ; 23)$ \\
$\quad$ oral antidiabetics & 27 \\
insulin & 9 \\
Complicatons/risk factors & \\
$\quad$ Smoking (current/former/non-smoker/ & $13 / 20 / 24 / 5$ \\
$\quad$ not stated) & \\
$\quad$ Hypertension & 50 \\
$\quad$ Dyslipidemia & 55 \\
History of vascular diseases & $42 / 19 / 15 / 13 / 8$ \\
(any coronary artery disease/angina & \\
pectoris/myocardial infarction/stroke/car- & \\
diostimulator) & \\
Polyneuropathy & \\
Nephropathy & 20 \\
PAD symptoms & 2 \\
Fontaine I & \\
Fontaine II & 40 \\
\hline
\end{tabular}

However, when using the guideline-recommended cut-offs, a mere $83 \%$ sensitivity, combined with a false positive rate of $20 \%$, PPV $77 \%$ and NPV $86 \%$ suggests that even this method is far from perfect in diabetic patients. Including all limbs with an abnormal ABI (i.e., including those with $\mathrm{ABI}>1.4$ and those in whom the measurements failed) as PAD-positive into the dataset improved both the sensitivity and negative predictive value. Even so, with the sensitivity of $87 \%$ and an NPV of $86 \%$, there is still a risk of underdiagnosis.

As far as the ABI LABP cut-off is concerned, the cutoff of 1.0 provides slightly better test parameters for a screening test (sensitivity 92\%, NPV 87\%) than the cut-

Table 2. Test parameters of different ABI calculations with ABI cut-off values of 0.9 and 1.0.

\begin{tabular}{|c|c|c|c|c|c|c|c|c|c|c|c|}
\hline \multirow{3}{*}{$\begin{array}{c}\text { ABI } \\
\text { affliction } \\
\text { cut-off }\end{array}$} & & \multicolumn{5}{|c|}{$\begin{array}{l}\text { Only patients } \\
\text { with } A B I<1.4\end{array}$} & \multicolumn{5}{|c|}{$\begin{array}{l}\text { All patients, } \\
\text { any abnormality in ABI denotes disease }\end{array}$} \\
\hline & & $\mathrm{ABI}$ & $\mathrm{ABI}$ & $\mathrm{ABI}$ & $\mathrm{ABI}$ & $\mathrm{ABI}$ & $\mathrm{ABI}$ & $\mathrm{ABI}$ & ABI & $\mathrm{ABI}$ & $\mathrm{ABI}$ \\
\hline & & ATA & ATP & HABP & LABP & OSC & ATA & ATP & HABP & LABP & OSC \\
\hline \multirow{6}{*}{0.9} & Sensitivity & 74.0 & 69.2 & 54.5 & 83.3 & 48.9 & 78.7 & 73.8 & 67.2 & 86.9 & 60.7 \\
\hline & Specificity & 81.0 & 86.2 & 87.0 & 80.0 & 95.2 & 74.6 & 79.4 & 74.6 & 76.2 & 93.7 \\
\hline & PPV & 77.1 & 81.8 & 77.4 & 76.9 & 88.5 & 75.0 & 77.6 & 71.9 & 77.9 & 90.2 \\
\hline & NPV & 78.3 & 75.8 & 70.1 & 85.7 & 71.1 & 78.3 & 75.8 & 70.1 & 85.7 & 71.1 \\
\hline & False pos rate & 19.0 & 13.8 & 13.0 & 20.0 & 4.8 & 25.4 & 20.6 & 25.4 & 23.8 & 6.3 \\
\hline & False neg rate & 26.0 & 30.8 & 45.5 & 16.7 & 51.1 & 21.3 & 26.2 & 32.8 & 13.1 & 39.3 \\
\hline \multirow{6}{*}{1.0} & Sensitivity & 84.0 & 78.8 & 70.5 & 89.6 & 78.7 & 86.9 & 82.0 & 78.7 & 91.8 & 83.6 \\
\hline & Specificity & 56.9 & 72.4 & 74.1 & 55.0 & 76.2 & 52.4 & 66.7 & 63.5 & 52.4 & 74.6 \\
\hline & PPV & 62.7 & 71.9 & 68.9 & 61.4 & 71.2 & 63.9 & 70.4 & 67.6 & 65.1 & 76.1 \\
\hline & NPV & 80.5 & 79.2 & 75.5 & 86.8 & 82.8 & 80.5 & 79.2 & 75.5 & 86.8 & 82.5 \\
\hline & False pos rate & 43.1 & 27.6 & 25.9 & 45.0 & 23.8 & 47.6 & 33.3 & 36.5 & 47.6 & 25.4 \\
\hline & False neg rate & 16.0 & 21.2 & 29.5 & 10.4 & 21.3 & 13.1 & 18.0 & 21.3 & 8.2 & 16.4 \\
\hline
\end{tabular}


Table 3. Confusion matrices for individual variants of $\mathrm{ABI}$ LABP calculations.

\begin{tabular}{llrrr}
\hline ABI criteria for PAD detection & \multicolumn{3}{c}{ Occlusion/stenosis $>50 \%$} \\
& & yes & no & $\sum$ \\
\hline ABI LABP $<0.9$; values & yes & 40 & 12 & 52 \\
$>1.4$ or test failures & no & 8 & 48 & 56 \\
excluded & $\sum$ & 48 & 60 & 108 \\
\hline ABI LABP $<1$; values & yes & 43 & 27 & 70 \\
$>1.4$ or test failures & no & 5 & 33 & 38 \\
excluded & $\sum$ & 48 & 60 & 108 \\
\hline ABI LABP $<0.9$ or $>1.4$ & yes & 53 & 15 & 68 \\
or measurement failure & no & 8 & 48 & 56 \\
& $\sum$ & 61 & 63 & 124 \\
\hline ABI LABP $<1$ or $>1.4$ & yes & 56 & 30 & 86 \\
or measurement failure & no & 5 & 33 & 38 \\
& $\sum$ & 61 & 63 & 124 \\
\hline
\end{tabular}

off 0.9 (sensitivity $87 \%$, NPV 86\%). On the other hand, however, a closer look at Table 3 reveals that a test with a cut-off 1.0 can only exclude 38 out of 124 limbs (31\%) from further examinations. On the other hand, the guideline-recommended cut-off of 0.9 can do the same for $45 \%$ of limbs, albeit with a negligibly worse reliability. A relatively minor increase of sensitivity with cut-off 1.0 by $5 \%$ therefore leads to a reduction in the number of patients who can be excluded from further examination by approx. $30 \%$. The question of cost effectiveness enters the equation now; we believe that such a trade-off would not be justifiable and the guideline-recommended cut-off of 0.9 should be adhered to in diabetic patients.

Oscillometric measurement resulted in characteristics complementary to those of ABI LABP. While specificity and positive predictive values were high, sensitivity and NPV were poor. We can therefore be relatively certain that patients who have abnormal ABI OSC result have PAD. However, we also know that, due to low sensitivity, almost $40 \%$ of patients who have PAD will not be captured. Therefore, ABI OSC is actually useless for screening in diabetic population. Patients tested positive have to be examined further. Due to the high number of false negatives in this test, however, patients tested negative cannot be considered PAD-free either and must be subject to additional examination as well.

Increasing the cut-off to 1.0 led to worse test parameters for ABI OSC - the cut-off increase lead to a small improvement of (poor) sensitivity at the expense of further deterioration of parameters that were relatively good with cut-off 0.9 .

The guideline-recommended HABP calculation yielded the worst results of the three methods in diabetic patients. It was closer in character to the oscillometric measurement, i.e., with better specificity and PPV than sensitivity and NPV but in none of the variants did the parameters justify using it as a screening tool.

An additional question is whether the patients with high ABI or test failure should be automatically considered as PAD positive. The results suggest that including these patients into the calculation of test parameters had no notable negative effect on the test performance, quite the contrary. Therefore, these patients should be considered as likely to have PAD and always sent for further examination (bear in mind that we are discussing a screening test now, not a diagnostic test). Such a decision is also supported by the conclusions of Aboyans $^{7}$ and others ${ }^{8,9}$ that high ABI bears a significant risk of development of serious complications and should be considered as PADequivalent ${ }^{7}$.

In the literature, the evidence concerning the use of oscillometric automated devices for ABI measurement varies throughout studies. In the study of Aboyans ${ }^{19}$, which was the only study focused specifically on diabetic patients, the results were poor and the use of oscillometric devices was not recommended. Our results are in good agreement with theirs. On the other hand, Massmann ${ }^{15}$ reported excellent correlation between the use of their automated oscillometric device and $\mathrm{ABI}$ determined by Doppler measurement, even in the subgroup of diabetic patients. However, they used ABI HABP for the comparison and they did not report the relationship between $A B I$ values and actual PAD presence. We can confirm similar trends between the guideline-recommended HABP and $\mathrm{ABI}$ OSC, although the test parameters for ABI OSC were systematically better than those for ABI HABP.

Table 4. Test parameters for ABI use for screening of PAD.

\begin{tabular}{lcccccc}
\hline Authors & Sensitivity & Specificity & PPV & NPV & Group size & Ref. \\
\hline Janssen A. & 71 & 42 & - & - & 106 & 26 \\
Premalatha G et al.* & 71 & 89 & 53 & 94 & 100 & 27 \\
Williams DT et al.** & $100 / 53$ & $88 / 95$ & - & $70 / 80$ & 68 & 28 \\
Parameswaran GI et al. & 53 & 97 & - & - & 57 & 29 \\
Hur KY et al. & 17 & 99 & 75 & 89 & 309 & 30 \\
Clairotte C et al. & $54 / 29$ & $97 / 96$ & $93 / 83$ & $75 / 66$ & 146 & 31 \\
Aboyans V et al. & 67 & 93 & 73 & 91 & 54 & 19 \\
Vogelberg KH*** & 36 & 93 & 70 & 75 & 48 & 32 \\
\hline
\end{tabular}

*mean of ankle systolic blood pressures used; **diabetic patients without/with peripheral neuropathy; ***mode of ABI calculation not stated; compared to angiography; ${ }^{+} \mathrm{ABI} \mathrm{HABP} / \mathrm{ABI}$ OSC; ${ }^{++} \mathrm{ABI}$ OSC values with Doppler ABI used as a golden standard 
Table 4 summarizing studies focused on the use of $\mathrm{ABI}$ in diabetic patients shows that the only test parameter on which the studies agree is high specificity. This is also in agreement with our results using the guideline-recommended parameters $(\mathrm{ABI}<0.9, \mathrm{HABP})$. The negative predictive value detected for these parameters in our study was $70 \%$, which is also on par with some of the results reported elsewhere. Similarly, the sensitivity of 54\% also matches or exceeds values reported in most of the other studies. Nevertheless, it must be taken into account that the studies suffer from notable methodical differences and that a simple comparison is not possible.

In conclusion, we can agree with the findings from other studies ${ }^{10-12}$ that the use of the lower ankle pressures leads to a better screening performance of ABI than the guideline-recommended method. Our study confirms this for the high risk subgroup of diabetic patients. We can also recommend considering any abnormality in ABI measurement (i.e., not just ABI below 0.9 but also abnormally high $\mathrm{ABI}$ or failure to measure any of the pressures) as a marker of possible PAD and referring such patients for further examination. Increasing the cut-off value from 0.9 to 1.0 led to a minor improvement in sensitivity, it was however at the expense of a significantly increased number of false positives. In effect, the number of patients who could thus be relatively safely excluded from further examinations dropped from $45 \%$ to $31 \%$. In our opinion, such a trade-off would not be beneficial and we cannot recommend the change of the cut-off to 1.0 in diabetic patients.

The use of oscillometric measurement in our study resulted in a very good specificity and positive predictive values for the cut-off of $\mathrm{ABI}<0.9$; however, the low sensitivity and therefore a high false negative rate prevents us from recommending it for screening of PAD in diabetic patients.

\section{CONCLUSION}

Using the lower ankle pressure for ABI calculation in diabetic patients yielded the best test parameters, especially where negative predictive value and sensitivity is concerned. Specificity and positive predictive values were however not too high. This indicates that the use of $\mathrm{ABI}$ in diabetic patients is suitable rather for identification of patients who do not need any further examination than for a reliable identification of patients with PAD. Increasing the lower cut-off to 1.0 would not lead to any improvement of screening test performance. Patients with any abnormality in ABI $(<0.9,>1.4$ or measurement failure) should be referred to further examination, e.g. duplex ultrasonic examination.

Acknowledgement: We would like to thank Jaroslav Janosek for his valuable comments and edits that contributed towards this study.

Author contributions: $\mathrm{MH}$ : study design, data collection and evaluation, manuscript writing; OM: data recording and evaluation; MP: manuscript writing, MK:- study design, manuscript writing; JP: data collection and manuscript review; DS: data collection and manuscript review. Conflict of interest statement: The authors state that there are no conflicts of interest regarding the publication of this article.

\section{REFERENCES}

1. GBD2016, Global, Regional, and National Incidence, Prevalence, and Years Lived with Disability for 328 Diseases and Injuries for 195 Countries, 1990-2016: A Systematic Analysis for the Global Burden of Disease Study 2016. Lancet 2017;390(10100):1211-59.

2. ADA ADA, Peripheral Arterial Disease in People with Diabetes. Diabetes Care 2003;26(12):3333-41.

3. Hennion DR, Siano KA. Diagnosis and Treatment of Peripheral Arterial Disease. Am Fam Physician 2013;88(5):306-10.

4. Gerhard-Herman MD, Gornik HL, Barrett C, Barshes NR, Corriere MA, Drachman DE, Fleisher LA, Fowkes FG, Hamburg NM, Kinlay S, Lookstein R, Misra S, Mureebe L, Olin JW, Patel RA, Regensteiner JG, Schanzer A, Shishehbor MH, Stewart KJ, Treat-Jacobson D, Walsh ME. 2016 Aha/Acc Guideline on the Management of Patients with Lower Extremity Peripheral Artery Disease: Executive Summary: A Report of the American College of Cardiology/American Heart Association Task Force on Clinical Practice Guidelines. J Am Coll Cardiol 2017;69(11):1465-508.

5. Rooke TW, Hirsch AT, Misra S, Sidawy AN, Beckman JA, Findeiss LK, Golzarian J, Gornik HL, Halperin JL, Jaff MR, Monet GL, Olin JW, Stanley JC, White CJ, White JV, Zierler R, Hirsch AT, Haskal ZJ, Hertzer NR, Bakal CW, Creager MA, Halperin JL, Hiratzka LF, Murphy WR, Olin JW, Puschett JB, Rosenfield KA, Sacks D, Stanley JC, Taylor LM Jr, White CJ, White JV, White RA, Jacobs AK, Anderson JL, Albert N, Creager MA, Ettinger SM, Guyton RA, Halperin JL, Hochman JS, Kushner FG, Magnus Ohman E, Stevenson W. 2011 Accf/Aha Focused Update of the Guideline for the Management of Patients with Peripheral Artery Disease (Updating the 2005 Guideline): A Report of the American College of Cardiology Foundation/American Heart Association Task Force on Practice Guidelines. Circulation 2011;124(18):2020-45.

6. Aboyans V, Ricco J-B, Bartelink M-L, Björck M, Brodmann M, Cohnert T, Collet J-P, Czerny M, De Carlo M, Debus S, Espinola-Klein C, Kahan T, Kownator S, Mazzolai L, Naylor RA, Roffi M, Röther J, Sprynger M, Tendera M, Tepe G, Venermo M, Vlachopoulos C, Desormais I. 2017 Esc Guidelines on the Diagnosis and Treatment of Peripheral Arterial Diseases, in Collaboration with the European Society for Vascular Surgery (Esvs). European Heart Journal 2017;00:1-60.

7. Aboyans V, Ho E, Denenberg JO, Ho LA, Natarajan L, Criqui MH. The Association between Elevated Ankle Systolic Pressures and Peripheral Occlusive Arterial Disease in Diabetic and Nondiabetic Subjects. J Vasc Surg 2008;48(5):1197-203.

8. Zhang H, Li XY, Si YJ, Lu XL, Luo XS, Liu ZY. Manifestation of Lower Extremity Atherosclerosis in Diabetic Patients with High AnkleBrachial Index. Chin Med J (Engl) 2010;123(7):890-4.

9. Singh GD, Armstrong EJ, Waldo SW, Alvandi B, Brinza E, Hildebrand J, Amsterdam EA, Humphries MD, Laird JR. Non-Compressible Abis Are Associated with an Increased Risk of Major Amputation and Major Adverse Cardiovascular Events in Patients with Critical Limb Ischemia. Vasc Med 2017; 22(3):210-217.

10. Aerden D, Massaad D, von Kemp K, van Tussenbroek F, Debing E, Keymeulen B, Van den Brande P. The Ankle--Brachial Index and the Diabetic Foot: A Troublesome Marriage. Ann Vasc Surg 2011;25(6):770-7.

11. Espinola-Klein C, Rupprecht HJ, Bickel C, Lackner K, Savvidis S, Messow CM, Munzel T, Blankenberg S. Different Calculations of Ankle-Brachial Index and Their Impact on Cardiovascular Risk Prediction. Circulation 2008;118(9):961-7.

12. Schroder F, Diehm N, Kareem S, Ames M, Pira A, Zwettler U, Lawall H, Diehm C. A Modified Calculation of Ankle-Brachial Pressure Index Is Far More Sensitive in the Detection of Peripheral Arterial Disease. J Vasc Surg 2006;44(3):531-6.

13. Takahashi I, Furukawa K, Ohishi W, Takahashi T, Matsumoto M, 
Fujiwara S. Comparison between Oscillometric- and Doppler-Abi in Elderly Individuals. Vasc Health Risk Manag 2013;9:89-94.

14. Span M, Gersak G, Millasseau SC, Meza M, Kosir A. Detection of Peripheral Arterial Disease with an Improved Automated Device: Comparison of a New Oscillometric Device and the Standard Doppler Method. Vasc Health Risk Manag 2016;12:305-11.

15. Massmann A, Stemler J, Fries P, Kubale R, Kraushaar LE, Buecker A. Automated Oscillometric Blood Pressure and Pulse-Wave Acquisition for Evaluation of Vascular Stiffness in Atherosclerosis. Clin Res Cardiol 2017:106(7):514-524.

16. Benchimol A, Bernard V, Pillois X, Hong NT, Benchimol D, Bonnet J. Validation of a New Method of Detecting Peripheral Artery Disease by Determination of Ankle-Brachial Index Using an Automatic Blood Pressure Device. Angiology 2004;55(2):127-34.

17. Beckman JA, Higgins CO, Gerhard-Herman M. Automated Oscillometric Determination of the Ankle-Brachial Index Provides Accuracy Necessary for Office Practice. Hypertension 2006;47(1):358.

18. Nukumizu Y, Matsushita M, Sakurai T, Kobayashi M, Nishikimi N, Komori K. Comparison of Doppler and Oscillometric Ankle Blood Pressure Measurement in Patients with Angiographically Documented Lower Extremity Arterial Occlusive Disease. Angiology 2007;58(3):303-8.

19. Aboyans V, Lacroix P, Doucet S, Preux PM, Criqui MH, Laskar M Diagnosis of Peripheral Arterial Disease in General Practice: Can the Ankle-Brachial Index Be Measured Either by Pulse Palpation or an Automatic Blood Pressure Device? Int J Clin Pract 2008;62(7):1001-7.

20. Wohlfahrt $P$, Ingrischova $M$, Krajcoviechova $A$, Palous $D$, Dolejsova M, Seidlerova J, Galovcova M, Bruthans J, Jozifova M, Adamkova V, Filipovsky J, Cifkova R. A Novel Oscillometric Device for Peripheral Arterial Disease Screening in Everyday Practice. The Czech-Post Monica Study. Int Angiol 2011; 30(3): 256-61.

21. Hingorani A, LaMuraglia GM, Henke $P$, Meissner MH, Loretz $L$, Zinszer KM, Driver VR, Frykberg R, Carman TL, Marston W, Mills JL, Sr., Murad MH. The Management of Diabetic Foot: A Clinical Practice Guideline by the Society for Vascular Surgery in Collaboration with the American Podiatric Medical Association and the Society for Vascular Medicine. J Vasc Surg 2016;63(2 Suppl):3s-21s.

22. Frykberg RG, Zgonis T, Armstrong DG, Driver VR, Giurini JM, Kravitz SR, Landsman AS, Lavery LA, Moore JC, Schuberth JM, Wukich DK,
Andersen C, Vanore JV. Diabetic Foot Disorders. A Clinical Practice Guideline (2006 Revision). J Foot Ankle Surg 2006;45(5 Suppl):S1-66. 23. KDIGO, Kdigo 2017 Clinical Practice Guideline Update for the Diagnosis, Evaluation, Prevention, and Treatment of Chronic Kidney Disease-Mineral and Bone disorder (Ckd-Mbd). Kidney International Supplements 2017;7(1):1-59.

24. Aboyans V, Criqui MH, Abraham P, Allison MA, Creager MA, Diehm C, Fowkes FG, Hiatt WR, Jonsson B, Lacroix P, Marin B, McDermott MM, Norgren L, Pande RL, Preux PM, Stoffers HE, Treat-Jacobson D. Measurement and Interpretation of the Ankle-Brachial Index: A Scientific Statement from the American Heart Association. Circulation 2012;126(24):2890-909.

25. Criqui MH. Peripheral Arterial Disease--Epidemiological Aspects. Vasc Med 2001;6(3 Suppl):3-7.

26. Janssen A. Pulsatility Index Is Better Than Ankle-Brachial Doppler Index for Non-Invasive Detection of Critical Limb Ischaemia in Diabetes. Vasa 2005:34(4):235-41.

27. Premalatha G, Ravikumar R, Sanjay R, Deepa R, Mohan V. Comparison of Colour Duplex Ultrasound and Ankle-Brachial Pressure Index Measurements in Peripheral Vascular Disease in Type 2 Diabetic Patients with Foot Infections. J Assoc Physicians India 2002;50:1240-

28. Williams DT, Harding KG, Price P. An Evaluation of the Efficacy of Methods Used in Screening for Lower-Limb Arterial Disease in Diabetes. Diabetes Care 2005;28(9):2206-10.

29. Parameswaran Gl, Brand K, Dolan J. Pulse Oximetry as a Potential Screening Tool for Lower Extremity Arterial Disease in Asymptomatic Patients with Diabetes Mellitus. Arch Intern Med 2005;165(4):442-6.

30. Hur KY, Jun JE, Choi YJ, Lee YH, Kim DJ, Park SW, Huh BW, Lee EJ, Jee $\mathrm{SH}$, Huh KB, Choi SH. Color Doppler Ultrasonography Is a Useful Tool for Diagnosis of Peripheral Artery Disease in Type 2 Diabetes Mellitus Patients with Ankle-Brachial Index 0.91 to 1.40. 2018;42(1):63-73.

31. Clairotte C, Retout S, Potier L, Roussel R, Escoubet B. Automated Ankle-Brachial Pressure Index Measurement by Clinical Staff for Peripheral Arterial Disease Diagnosis in Nondiabetic and Diabetic Patients. Diabetes Care 2009;32(7):1231-6.

32. Vogelberg KH, Stork W. Measurement of Pulse Reappearance Time in Diagnosis of Peripheral Vascular Disease in Diabetes. Diabetes Care 1988:11(4):345-50. 